\title{
Evaluation of a Radiographic Method to Detect Tibial Dyschondroplasia Lesions in Broilers
}

\section{-Author(s)}

Pelicia K², Aparecido Jr IM³ , Garcia EA², Molino $\mathrm{AB}^{4}$, Santos $\mathrm{GC}^{4}$, Berto $\mathrm{DA}^{4}$, Vieira Filho $\mathrm{JA}^{4}$ Murakami ESM ${ }^{5}$, Montenegro $\mathrm{AT}^{5}$, Silva $\mathrm{AM}^{3}$

${ }^{1}$ Department of Animal Science of the School of Agriculture and Animals Science of University José do Rosário Vellano - UNIFENAS, Alfenas, MG, Brazil

${ }^{2}$ Ph.D., Head Professor of the Department of Animal Production, FMVZ/UNESP. Botucatu, SP, Brazil

${ }^{3}$ Student of Animal Science of the School of Agriculture and Animals Science of University José do Rosário Vellano - UNIFENAS. Alfenas, MG, Brazil

${ }^{4}$ Students of the Post-Graduation Program in Animal Science of FMVZ/UNESP. Botucatu, SP, Brazil

${ }^{5}$ Undergraduate students of the course of Animal Science of FMVZ/UNESP and UNIFENAS

\section{-Mail Adress}

* Corresponding author:

Kleber Pelícia

Department of Animal Science/ Agronomy UNIFENAS/ALFENAS, MG - Brazil

Rod. MG 179, Km 0 Campus Universitário CEP: 37.130-000 - Alfenas/MG - Brazil

E-mail: kleber.pelicia@unifenas.br

\section{EKeywords}

Broiler production, histology, gross examination, radio-diagnosis, tibia.

\section{ABSTRACT}

This study aimed at developing radiographic techniques for the early detection of dyschondroplastic lesions in the tibia of broilers. The experiment was carried out at the facilities of UNIFOR/MG and Formiga and UNIFENAS/ Alfenas with 420 one-day-old male Cobb broilers. At 20 days of age, all birds were radiographed and identified with an alpha-numeric metal ring in the right leg. At 40 days of age, 42 broilers previously selected as a function of bone mineral density and lesion thickness scores were again radiographed and scored, and then sacrificed. Their right tibia was removed for gross and histological examination of the growth plate. The results showed that radiographic techniques are correlated with gross and histological examination and that there was no significant differences among techniques ( $P>0.05$ ). it was concluded that the use of radiographic examination to identify tibial dyschondroplasia in broilers precludes the use of bone mineral density to diagnose this condition. The non-parametric statistical Chi-square test at $5 \%$ significance level was used to analyze the results.

\section{INTRODUCTION}

The pathologies that affect the locomotion system of confined animals may have a major impact on the profitability of livestock production, as it negatively affects animal performance and welfare (Almeida Paz et al., 2009). Poultry companies prefer buying birds that present high carcass yield potential, and together with the global trend of a higher consumption of chicken parts, the broiler industry tends to produce broilers of fast-growing genetic lines (Gonzales \& Macari, 2000).

Poultry with leg deficiencies are deprived for locomotion freedom. And as there are no intermediate score for this freedom, it is almost unavoidable that birds suffer discomfort, fear and distress during the growout, even if temporarily. Therefore, researchers have sought for detailed information on the development of locomotion problems, aiming at determining techniques that may aid identifying and, consequently, alleviating leg problems in poultry (Nãas, 2008).

In commercial processing plants, about 3.3\% of broiler carcasses are condemned due to overt leg problems and $27.6 \%$ due locomotion problems, and this is directly related to growth rate (Knowles et al., 2008). Losses are not limited to increased mortality and culling during the growout, which represent only a small portion of the economic impact of these problems. The increase in carcass condemnations in the processing plants due to skin and joint inflammation, chemical dermatitis and blisters because birds remain sitting longer, higher contamination rates with consequent risks to food safety, and problems in the processing line are the main causes of these economic losses. Current statistics suggest that total or partial carcass condemnation due to leg problems significantly increase the cost per $\mathrm{kg}$ of live weight (Knowles et al., 2008). 
Another important factor is the increase in the energy required for locomotion. Gonzales \& Macari (2000) estimated that, depending on the degree of impairment, the energy required for locomotion may increase between 20 and $60 \%$. This increase in maintenance requirements uses part of the energy that could be used for tissue accretion, leading to weight losses and lack of flock uniformity. The increase in energy requirements for maintenance, high prevalence in broiler flocks, and potential problems during processing and in the final product caused by leg problems demonstrates the importance of their evaluation and the search for solutions (Gonzales \& Macari, 2000).

Tibial dyschondroplasia is one of the most frequent leg problems, and may have 30\% prevalence in a broiler flock. It is clinically detectable in broilers older than 35 days of age (Crespo \& Shivaprasad, 2003 and Knowles et al., 2008). That deformity may affect several fast-growing poultry species, and it is characterized by an avascular cartilage mass below the growth line at the proximal metaphysis of the tibiotarsus. This cartilage mass is caused by the persistence and accumulation of pre-hypertrophic cartilage between the pre-hypertrophic and hypertrophic layers (Crespo \& Shivaprasad, 2003).

Tibial dyschondroplasia is an abnormality of the growth plates of the epiphysis of the long bones that is characterized by the presence of a dull white avascular cartilage mass that extends until the metaphysis, where trabecular bone is usually present (Capela and Silva et al., 2010).

The evaluation of the thickness of the dyschondroplastic lesion can be made using radiographic images and light focus, and does not require scanners or specific software programs, as previously used by Almeida Paz et al., (2005), thereby reducing the cost and time required for the evaluation (Pelicia et al., 2011). This study aimed at evaluating improvements in radiographic techniques for the early detection of dyschondroplastic lesions in the tibia of broilers.

\section{MATERIALS AND METHODS}

A flock of 420 one-day-old 420 male COBB, (GC44/ COBBS/12700; BC33/COBBS/11300) broilers was reared until slaughter, at 40 days of age at UNIFENAS, Brazil. The experimental procedures were approved by the Committee on Ethics of UNIFENAS (protocol number 8 a - 2010).

Broilers were reared according to a typical commercial management system in floor pens, and received feed and water ad libitum.

\section{Radiographic examination}

\section{Equipment}

A conventional radio-diagnosis apparatus (EQUIMEX, Mexico) at $200 \mathrm{mAs}$ and $100 \mathrm{kVp}$, and $X$-ray generator and turning anode, was used. All radiographic examinations followed the methodology described in Almeida Paz et al. (2005).

\section{Radiographic technique}

The X-ray apparatus was calibrated to a $90-\mathrm{cm}$ focus-film distance, with $45 \mathrm{kVp}$ and $4.0 \mathrm{mAs}$ in all evaluations (Almeida Paz et al., 2005).

\section{Radiograph analysis}

All radiographic images were individually analyzed, and the radiographic changes found in the affected tibia, proximal fibula, and distal femur of the right leg were described.

\section{Software program used for image analysis}

The radiographic images were digitalized using a table scanner (Hewlett-Packard, model Scanjet 6300C) with a slide adapter (Hewlett-Packard, model ScanJet XPA).

\section{First experiment}

At 20 days of age, 420 broilers were randomly selected from a flock of 24,000 birds, placed in transport crates and sent to the radio-diagnosis sector of the School of Veterinary Medicine of UNIFOR/MG, Brazil.

All birds were identified with an alpha-numeric ring in the right leg, and then the proximal region of the tibia and of the fibula and the distal region of the femur of the right leg were radiographed.

The following scores were attributed to the radiographic images: 0 (zero) indicated that there were no lesion, i.e., the proximal region of the tibia presented regular and well-defined edges; 1 (one) when there was a small $(1-3 \mathrm{~mm})$ transparent lesion, with sclerosis of the subchondral bone; 2 (two) represented an intermediate lesion, measuring 3-6mm, when the radio-transparent region partially covered the epiphysis of the tibia and the tibial plateau was not visible, and presented irregular edges and bone 
deformity; and 3 (three) represented a large lesion, measuring more than $6 \mathrm{~mm}$, when bone edges were hardly recognizable because the radio-transparent region covers the entire bone epiphysis and there are radiological characteristics of sclerosis, thinning of the cortical region, thickening or reduction of the joint space, and in some cases, mechanic restriction and fractures (Almeida Paz et al., 2005).

Using a software program to analyze the radiograph images, 23 broilers received score 1; seven received score 2 and no birds received 3 . Twelve broilers with score zero, selected from the original flock, were added to complete the number of 42 broilers required by the experimental design.

After the radiographic examination, during the interval of 20 days until the second evaluation, broilers remained in the poultry house of UNIFOR-MG and were housed at a density of $10 \mathrm{birds} / \mathrm{m}^{2}$, receiving feed and water ad libitum until 40 days of age. The broilers were not returned to their original flock for biosecurity reasons.

\section{Second experiment}

At 40 days of age, the 42 broilers selected for the first evaluation were again radiographed and scored in order to compare with the results of the first experiment. Radiographic images were analyzed with or without aluminum, and the same tibial dyschondroplasia were obtained. Images with aluminum were evaluated according to bone mineral level, and the images without aluminum were evaluated according to lesion size. Higher scores represent bigger lesions.

The densitometric reference was made of aluminum alloy, which density is very similar to that of hydroxyapatite that is the form calcium and phosphorus are stored in the bone (Almeida Paz et al., 2005).

Bone mineral density was determined by regular radiograph of the right tibia, together and simultaneously to the aluminum scale made of specific and internationally standardized alloy (Liga de alumínio 2026, ABNT).

\section{Gross examination}

After the radiographic examination, birds were sacrificed and their right leg, previously identified with a ring, was removed. Legs were dissected with a scalpel; the tibiae were axially cut $5 \mathrm{~cm}$ from the proximal epiphysis using a steel saw, and the placed in a flask containing buffered formalin at 10\%. Twenty- four hours later, the specimens were submitted to gross examination and scored according to a 0-3 scale, where 0 indicated that the growth plate of the epiphysis was not thickened, 1 indicated mild growthplate thickening (1-3mm, approximately), 2 indicated growth-plate thickening of $3-6 \mathrm{~mm}$, and 3 that that the growth plate was thicker than $6 \mathrm{~mm}$, according to Almeida Paz et al. (2005).

Specimens were then immediately submitted to the pathology sector of the University of Alfenas (UNIFENAS) for histological examination.

\section{Histological examination}

At the pathology sector of the University of Alfenas (UNIFENAS), bones were de-calcified and dehydrated, after which the tibiae were transversally cut into $7 \mu \mathrm{m}$ thick sections with the aid of a microtome, and stained with hematoxylin and eosin (HE) (Almeida Paz et al., 2005).

Chondrocytes were isolates from small cavities of the bone tissue called gaps. Gaps, isogenic groups, or chondroplasts characterize the cartilage tissue. Chondrocytes are round, have a basophile cytoplasm, and contain large amounts of endoplasmic reticulum. They contribute for the diagonal growth of cartilage, when mitotic cell division and the excretion of more matrix among daughter cells allow the expansion of the cartilage (Takita, 1998).

According to Almeida Paz et al. (2005), the growth plate is divided into a proliferative zone, a pre-hypertrophic zone, and a hypertrophic zone. The following scores, based on Almeida Paz et al. (2005), were attributed the examined growth plate sections: 0 (zero) indicated normal growth plates, with clear differentiation of the three zones; 1 indicated regions of accumulation of pre-hypertrophic chondrocytes in some regions of the growth plate; 2 indicated that the growth plate presented a wide and distinct band of pre-hypertrophic chondrocytes; and 3 degenerative changes.

\section{STATISTICAL ANALYSIS}

The statistics used to analyze the results of the present study was non-parametric, as scores were compared. Data were submitted to the Chi-Square test at $5 \%$ significance level. Means were compared by the test of Kruskall-Wallis. Data were analyzed using the statistical package developed by the Federal University of Viçosa (2007), SAEG, version 9.1. 


\section{RESULTS AND DISCUSSION}

It was possible to establish confidence intervals for bone mineral density as a function of the tibial dyschondroplasia histological scores in 40-d-old broilers.

The histological score results (Table 1) showed that, when bones were score 1, they presented mild dyschondroplastic lesion and bone mineral density between 1.89 and $2.18 \mathrm{mmAl}$ (millimeters of aluminum). When bones were scored 2 , bone mineral density was between 1.45 and $1.85 \mathrm{mmAl}$, with an intermediate lesion between scores 1 and 3 . Bone mineral density values of 1.03 and $1.42 \mathrm{mmAl}$ were determined when severe lesions, with histological score was 3. Bone mineral density values for bones scored as normal (score zero) were between 2.21 and $2.61 \mathrm{mmAl}$ (Table 1). It must be noted that, when lesions are severe, the amount of aluminum is lower, not higher.

Barreiro et al., (2009) determined as normal bone densitometric values of $2.31 \mathrm{mmAl}$ for the femur of grower broilers. Lousada (1997) established as normal values between 1.77 and $1.97 \mathrm{mmAl}$ for the central region of the diaphysis of tibia of 35-d-old broilers, as determined by optical radiographic density; however, this region does not present bone growth and its mineralization is more stable than the metaphysis and the epiphysis.

Almeida Paz et al. (2005) found higher bone mineral density values than those determined in the present study, varying between 3.57 and $4.33 \mathrm{mmAl}$ for score 1 , whereas sections with score 5 , presenting severe lesions, had bone mineral density values between 1.60 and $2.21 \mathrm{mmAl}$ in 40-d-old broilers. Almeida Paz et al. (2005) radiographed the head and the neck of the femur, where bone mineral density is higher because the proximal region of the femur presents spongy bone shafts divided according to the force lines resulting from the local pressure on the higher extremity of the femur.

Table 1 - Histological scores and bone mineral density values of the lesions caused by tibial dyschondroplasia in 42-d-old broilers.

\begin{tabular}{c|c}
\hline TIBIAL DYSCHONDROPLASIA EVALUATION METHODS \\
\hline Histological lesion scores & Bone mineral density (mmAl) \\
0 & $2.21-2.61$ \\
1 & $1.89-2.18$ \\
2 & $1.45-1.85$ \\
3 & $1.03-1.42$ \\
\hline
\end{tabular}

Kruskal-Wallis ( $p>0.05)$; Histological scores: 0 (zero) absence of lesions; 1 indicates small lesion; 2 indicates intermediate lesion; and 3 indicates extensive lesion.
The difference in bone mineral density reference values (Table 1) obtained in the present study compared with other authors is explained by the fact that every author uses a different software program to analyze the images. In order to establish bone mineral density values to be used to diagnose pathologies that affect broilers, other factors must also be considered, such as body weight, type of lesion, etc.

Figure 1 shows a normal bone, with score zero. The red circle on the proximal tibia shows well-defined radiographic characteristics, regular edges, wellpreserved joint space, and no changes in the soft periarticular area, where the radiopaque image covers the entire region of the epiphysis and of the metaphysis.

Figure 2 shows a bone with score 3, with the use of an aluminum wedge for the evaluation of bone mineral density. The obtained value of $1.19 \mathrm{mmAl}$ is consistent with the reference values of 1.03 to 1.42 $\mathrm{mmAl}$, which indicate severe lesion.

In Figure 3, the pathological signs of increased lesion thickness are identified in the image, where the diameter of the circle shown in the picture below is measured and the results are expressed in $\mathrm{mm}$.

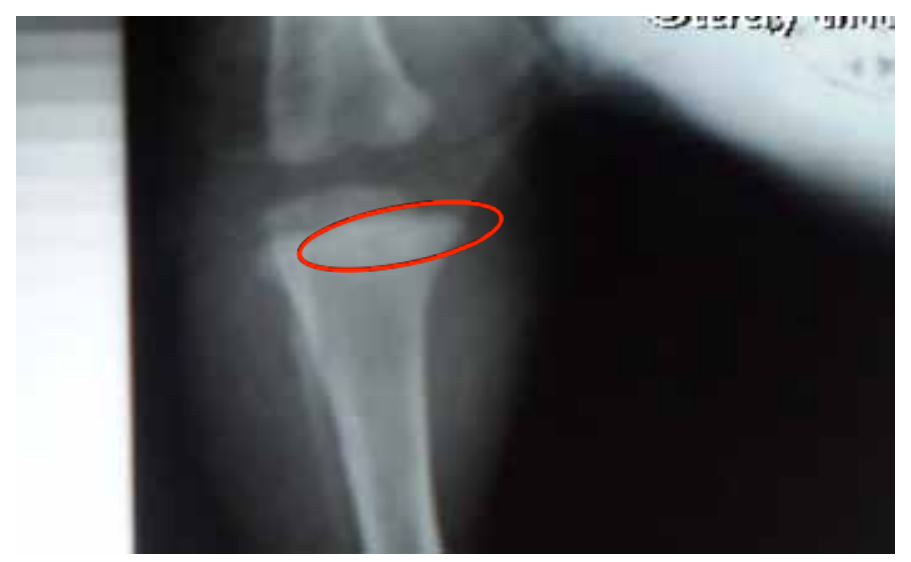

Figure 1 - Radiographic image of a normal bone (score zero).

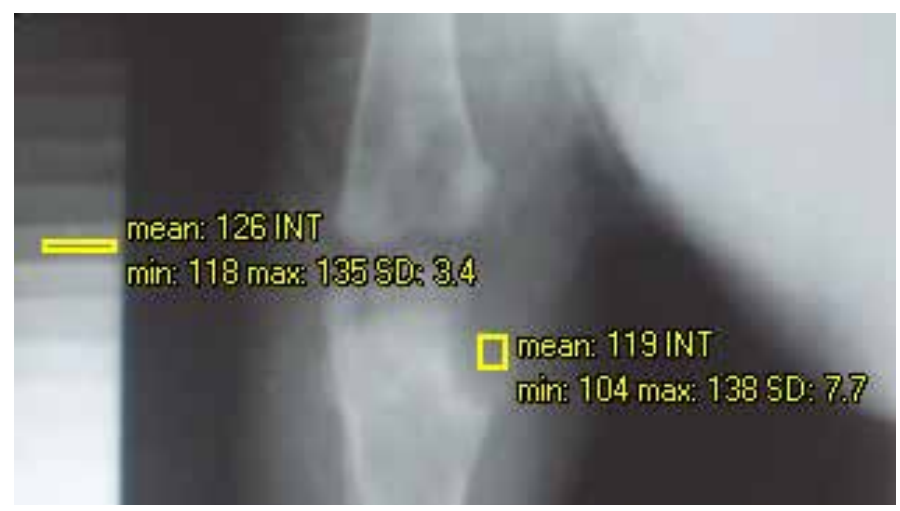

Figure 2 - Reference bone mineral density values for lesion score 3 


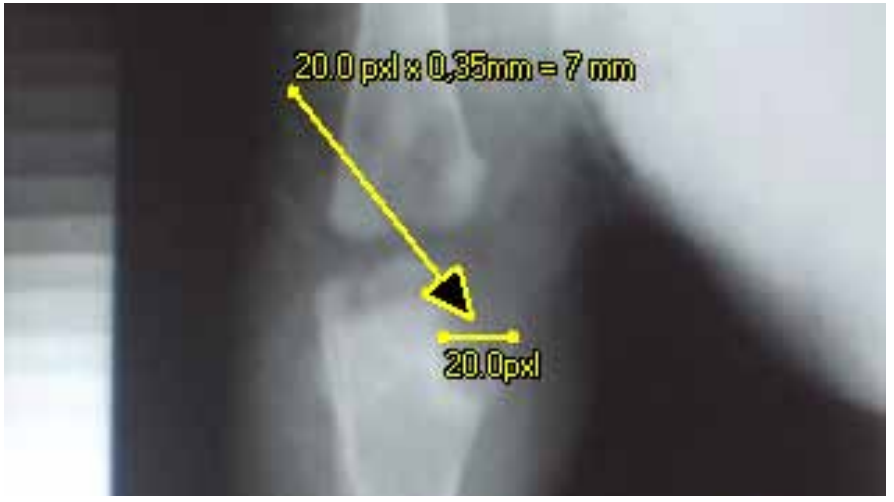

Figure 3 - Reference values of lesion thickness for lesion score 3.

The results obtained in the present study for scores 1 to 3 are similar to those described by Almeida et al., (2005), but using a different nomenclature (Figures 2 and 3, showing score 3), who determined higher scores as bone mineral density increased scores. The image presented in Figure 3 shows an extensive lesion, where bones edges are barely recognizable because the radiotransparent region covers almost the entire epiphysis of the tibia, presenting radiological characteristics of sclerosis, thinning of the cortical region, angle deformities, widening or reduction of the joint space. In some cases, this type of lesion result in mechanic restriction and fracture, extending for more than $6 \mathrm{~mm}$ mainly in the medial region of the tibia.

Lesion thickness is determined by the radiotransparent area, that is, the grey area shown in image (Figura 3) relative to the surrounding tissues. Monnier and Tubiana (1999) observed that the radiologic aspects periosteum and cartilage are radio-transparent. Those authors also mentioned that the density scale varies between white and black, that is, the radiopaque region appears as white in the radiographic image because the molecules are composed by heavy atoms and high calcium content, whereas the radio-transparent area appear as dark in the image. Onyango et al., (2003) used bone mineral density as an indicator of ash percentage in the tibia of broilers. In all radiographic images, liquids and soft tissues, including blood, muscle, cartilage, ligaments, and nerves, have the same density as water, and present greyish color (McKinnis, 2004).

According to Bernardino (2009), tibial dyschondroplasia is characterized by an abnormal non-vascular and poorly mineralized cartilage mass. Louzada et al. (1997) demonstrated that the tibial lesion is evidenced by the densitometry technique when the mean values, in $\mathrm{mm}$ of aluminum, of the radiographic image are compared with mean calcium percentage in the bone samples.

The lesion thickness results (Table 2) obtained from the radiographic images explain the scores 1 to 2 of the radio-transparent areas (Figure 3 ).

Table 2 - Gross lesion scores and radiographic lesions thickness of 42-d-old broilers.

\begin{tabular}{ll}
\hline TIBIAL DYSCHONDROPLASIA EVALUATION METHODS \\
\hline Gross lesion scores & Radiographic lesion thickness $(\mathrm{mm})$ \\
0 & $<-1$ \\
1 & $1-3$ \\
2 & $3-6$ \\
3 & $>-6$ \\
\hline
\end{tabular}

Kruskal-Wallis ( $p>0.05)$. Gross lesion scores: 0 (zero) absence of lesions; 1 indicates small lesion; 2 indicates intermediate lesion; and 3 indicates extensive lesion.

The techniques of bone mineral density evaluation and gross and histological lesion thickness evaluation are recommended as alternatives for leg pathology analysis in broilers.

Table 3 shows the results used for the diagnosis of tibial dyschondroplasia in 20- and 40-day-old broilers. No differences ( $p>0.05$ ) in dischondroplastic lesions were detected in the radiographic examination between 20 and 40 days of age. On the other hand, Barreiro et al. (2009) found increasing bone mineral density in broilers between the starter and the grower phase. According to those authors, the differences in the densitometric values of the tibiotarsus are related to mineralization and increasing bone strength due to muscle mass development.

Table 3 - Radiographic lesion scores of 20- and 40-d-old broilers.

\begin{tabular}{ccc}
\hline X-squared & Df & p-value \\
3.8125 & 2 & 0.148636731 \\
\hline Score & Frequency (n), 20 days & Frequency (n), 40 days \\
0 & 12 & 10 \\
1 & 23 & 15 \\
2 & 07 & 11 \\
3 & 0 & 06 \\
Total & 42 & 42 \\
\hline
\end{tabular}

Kruskal-Wallis $(p>0.05)$; $n=$ number of broilers. Radiographic lesion scores: 0 (zero) absence of lesions; 1 indicates small lesion; 2 indicates intermediate lesion; and 3 indicates extensive lesion.

The lack of differences in lesion score between the two ages (Table 3) may be explained by the fact that the lesion is observed in 3- to 5-week-old broilers. Lesion 
development, body weight, and bone mineral content, as well as nutrition, management, mycotoxins, and some di-thio-carbamates may induce the emergence and affect and incidence and the severity of dyschondroplastic lesions. According to Almeida Paz et al. (2005), this condition frequently appears when broilers are between 3 and 8 weeks of age; despite its low incidence $(2 \%)$, it causes poor performance and condemnation in the processing plant, resulting in relevant losses.

The results show that radiographic results are correlated with gross and histological examinations (Tables 4 and 5). Considering that the histological examination of the growth plate is $100 \%$ efficient when evaluating dyschondroplastic lesions (Vieites et al., 2005 and Almeida Paz et al., 2005), it provides higher reliability to the radiographic examinations in the detection of dyschondroplastic lesions in 20- and 40-d-old broilers, thereby preventing future processing losses. The values obtained with the radiographic analysis, using aluminum or not, are consistent with the scores obtained by gross and histological examinations.

Table 4 - Porcentage of dyschondroplastic lesions as detected by gross, histological, and radiographic (with or with no aluminum) examinations in 40-d-old broilers.

\begin{tabular}{lcccc}
\hline Method & \multicolumn{4}{c}{ Radiographic scores } \\
\hline & 0 & 1 & 2 & 3 \\
Radiograph (\%) & 23.8 & 35.72 & 26.19 & 14.29 \\
Gross examination (\%) & 23.8 & 35.72 & 26.19 & 14.29 \\
Histology (\%) & 23.8 & 35.72 & 26.19 & 14.29 \\
\hline
\end{tabular}

Kruskal-Wallis ( $p>0.05)$ : Radiographic lesion scores: 0 (zero) absence of lesions; 1 indicates small lesion; 2 indicates intermediate lesion; and 3 indicates extensive lesion.

Table 5 - Number of dyschondroplastic lesions as detected by gross, histological, and radiographic (with or with no aluminum) examinations in 40-d-old broilers.

\begin{tabular}{lcccc}
\hline Method & \multicolumn{4}{c}{ Radiographic scores } \\
\hline & 0 & 1 & 2 & 3 \\
Radiograph (\%) & 10 & 15 & 11 & 6 \\
Gross examination (\%) & 10 & 15 & 11 & 6 \\
Histology (\%) & 10 & 15 & 11 & 6 \\
\hline
\end{tabular}

Kruskal-Wallis ( $p>0.05$ ); Radiographic lesion scores: 0 (zero) absence of lesions; 1 indicates small lesion; 2 indicates intermediate lesion; and 3 indicates extensive lesion.

These results are consistent with those previously reported by Barreiro et al., (2011), who did not find any differences in the incidence of tibial dyschondroplasia as determined by lixiscope. However, Thorp et al., (1997) and Almeida Paz et al., (2005), observed significant differences $(p<0.01)$ between evaluations using lixiscope and gross and histological examinations. In the study of Almeida et al., (2005), four different methods were used: portable X-ray fluoroscope (lixiscope), radiographs (optical densitometry), and gross and histological examinations. The lixiscope was used to select broilers by scores, but it is no longer used. The dyschondroplastic lesions found by Almeida Paz et al., (2005), both using the lixiscope and radiographs, were characterized as being radiopaque. We believe these results are not correct, as dyschondroplastic lesions are radio-transparent because they are cartilaginous, amorphous, avascular mass with different sizes and are usually present low mineral content, depending on the severity of the lesion. Abnormal cartilage observed in the epiphysis disc is the persistence of pre-hypertrophic and hypertrophic chondrocytes, which was not invaded by the blood vessel from the metaphysis and is not submitted to calcification.

The diagnosis of the dyschondroplastic changes of the proximal region of the tibia of 20 - and $40-d$-old broilers can be made using the radiographic methods described in the present study, as they are easy to perform, cheap, and efficient.

The results obtained in the present study recommend the use of the radiographic examination to evaluate the status of the growth plate. The positive correlations of bone densitometry with other types of evaluations indicate it is feasible because, as compared to conventional analysis methods, it is able to reproduce the actual conditions of the growth plate. In addition, bone densitometry allows evaluating the depth of the lesion and, by determining cartilage thickness, to identify the size of the lesion.

Although further studies are required, it must be noted that radiographic examination allows the early detection of lesions in live broilers, thereby reducing condemnation in the processing line. This method can be an useful tool for poultry companies that aim at reducing this pathology in their commercial flocks.

The present study also showed that

This study also showed that bone mineral density is reduced as the severity of the tibial dyschondroplasia lesion increases, and not increases, are reported in previous studies.

The methods for the radiographic evaluation of bone mineral density (mmAl) and of lesion thickness ( $\mathrm{mm}$ ) are efficient for the diagnosis of tibial dyschondroplasia in broilers and require only the radiographic image and the light focus, and does not need scanners or specific 
software programs, reducing costs and time compare with other evaluations.

\section{CONCLUSION}

The results obtained in the present study indicate that the use of radiographic examination for the identification of dyschondroplasia in broilers is efficient, and that the determination bone mineral density is not required to diagnose dyschondroplastic lesions.

\section{REFERENCES}

Pelicia K, Aparecido Junior IM, Faitarone ABG, Molino AB da, Santos GC. Aperfeiçoamento da técnica radiográfica em lesão discondroplásica em frangos de corte. Anais do $23^{\circ}$ Congresso Brasileiro de Avicultura; 2011; Santos, São Paulo. Brasil.

Almeida I CL. Caracterização da discondroplasia tibial em frangos de corte através da densitometria óptica radiográfica. 2003. 53 f. Dissertação (Zootecnia) - Faculdade de Medicina Veterinária e Zootecnia Campus de Botucatu, São Paulo.

Alameida Paz ICL, Mendes AA, Takita TS. Comparison of techiniques for ibial dyschondroplasia assesment in broiler chickens. Brazillian Journal of Poultry Science 2001; 7(1): 27-31.

Barreiro FR, Baraldi-Artoni SM, Sagula AL, Junqueira OM. Comparação de parâmetros densiométricos de frangos de corte na fase inicial de desenvolvimento. In: SIICUSP - Simpósio Internacional de Iniciação Científica, 2007. 15, Pirassununga. Anais...

Bartels JE, McDaniel GR, Hoer FJ. Radiografhic diagnosis of tibial dyschondroplasia in Broilers: a field selection techinique. Avian Diseases 1989; 33: 254-257.

Crespo R, Shivaprasad H. Developmental, Metabolic, and Other Noninfectious disorders. In: Saif YM (Eds.). Diseases of Poultry. $11 \mathrm{Ed}$. Ames: lowa State Press, p. 1055-1102. 2003.

Gonzales E, Macari M. Doenças das Aves. Campinas: Editora Facta. 2000.

Louzada MJQ. Densidade de peças ósseas de frangos. Estudo pela densiometria óptica radiográfica. Veterinária e Zootecnia 1997; 9: 95109.

McKinnis LN. Fundamentos da Radiologia Ortopédica. São Paulo: Premier. 2004.

Mendonça JR. Enfermidade do Sistema Locomotor. In: Berchieri Júnior, A.: Macari, M. Doença das Aves. Campinas, Editora Facta, p. 29-36. 2000.

Monnier JP, Tubiana JM. Manual de diagnóstico radiológico. \%. ed. Rio de Janeiro: Médica e Científica. 1999.

Murakami A. Balanço eletrolítico da dieta e sua influência sobre o desenvolvimento dos ossos de frangos. In: Conferência Apinco 2000 de Ciência e Tecnologia Avícola, Anais...

Onyango EM, Hester PY, Stroshime R. Bone densiometry as an indicator of percentage tibia ash in broiler chicks fed varying dietary and phosphorus levels. Poultry Science 2003; 82(11): 1787-1791.

Oviedo-Rondón E. Leg health in large broilers. NC Broiler Supervisors' Short Course. 2008.

Oviedo-Rondón E. El sistema de producción avícola de carne: 1. El Modelo Americano. XXV Curso de Especialización FEDNA: Avances in Nutrición y Alimentación Animal. 2099a.

Oviedo-Rondón E. Aspectos nutricionales que influyen sobre la incidencia de problemas de patas en pollos de engorde. Curso de Especialización FEDNA: Avances in Nutrición y Alimentación Animal. 2099b.

Pizzauro Jr, Ciancaglini P, Macari M. Discondroplasia tibial: mecanismo de lesão e controle. Revista Brasileira de Ciência Avícola 2002; 4(3): 1-22.

Takita TS, Gonzales E, Loddi MM, Ramos AA. Métodos de avaliação de discondroplasia tibial em frangos de corte. In: Conferência Apinco de Ciência e Tecnologia Avícola, Anais..

Thorp BH, Dick L, Zefferies D, Houston B. An assessment of efficacy of the lixiscope for the detection of tibial dyschondroplasia. Avian Pathology 1997; 26: 97-104.

Universidade Federal de Viçosa - UFV. SAEG - Sistemas de análises estatísticas e genéticas. Versão 9.1. Viçosa, MG: 2007. 
